\title{
The Clinical Application of Core-Needle Biopsy after Radiofrequency Ablation for Low-risk Papillary Thyroid Microcarcinoma: A Large Cohort of 202 Patients Study
}

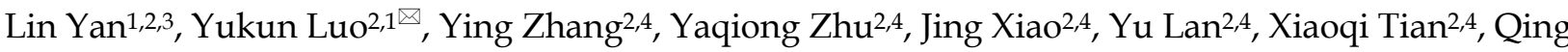 \\ Song ${ }^{2}$, Fang $\mathrm{Xie}^{2}$ \\ 1. Medical School of Chinese PLA, No.28 Fuxing Road, Haidian District, Beijing, China. \\ 2. Department of Ultrasound, First Medical Center, Chinese PLA General Hospital, No.28 Fuxing Road, Haidian District, Beijing, China. \\ 3. Health Management Center, The Second Hospital of Dalian Medical University, No.467 Zhongshan Road, Shahekou District, Dalian, China. \\ 4. School of Medicine, Nankai University, No.94 Weijing Road, Nankai District, Tianjing, China. \\ $\triangle$ Corresponding author: Yukun Luo, MD Tel: +8613311373556; Fax: +8601055499255; Email: lyk301@163.com
}

(c) The author(s). This is an open access article distributed under the terms of the Creative Commons Attribution License (https://creativecommons.org/licenses/by/4.0/). See http://ivyspring.com/terms for full terms and conditions.

Received: 2019.12.02; Accepted: 2020.06.13; Published: 2020.07.09

\begin{abstract}
Purpose: To evaluate the clinical application of core-needle biopsy (CNB) for low-risk papillary thyroid microcarcinoma (PTMC) after radiofrequency ablation (RFA)

Methods: A total of 202 patients with 211 low-risk PTMCs were included in this study. RFA procedure was used the hydrodissection technique and moving-shot technique. Patients were followed at 1, 3, 6, 12 months and every 6 months thereafter. The volume of ablation area and the volume reduction ratio (VRR) were calculated. At 3 or 6 months after RFA, CNB was performed to the central zone, the peripheral zone and surrounding thyroid parenchyma for post-ablation evaluation.

Results: The mean volume of tumors was $102.34 \pm 93.84 \mathrm{~mm}^{3}$ (range 4.19-424.10 $\mathrm{mm}^{3}$ ), which decreased significantly to $1.37 \pm 7.74 \mathrm{~mm}^{3}$ (range $0-73.30 \mathrm{~mm}^{3}$ ) at a mean follow-up time of $24.42 \pm 9.15$ months (range 3-42 months) with a mean VRR of $99.14 \pm 4.18 \%$ (range 71.88-100\%). A total of 3 ablation areas had positive CNB in the peripheral zone and underwent additional RFA. No recurrent or suspicious metastatic lymph nodes were detected

Conclusion: CNB is a feasible and effective evaluation for low-risk PTMC after RFA, which can detect residual cancer cells early.
\end{abstract}

Key words: radiofrequency ablation; papillary thyroid microcarcinoma; core-needle biopsy; ultrasound.

\section{Introduction}

Thyroid cancer is the most common malignancy of the endocrine system, which is responsible for 567,000 cases worldwide ranking in ninth place for incidence [1, 2]. Roughly $50 \%$ of this incidence is attributable to the identification of intrathyroidal papillary thyroid microcarcinoma (PTMC) [3]. PTMC is a form of papillary thyroid carcinoma (PTC) and defined by WHO as a tumor measuring $1.0 \mathrm{~cm}$ or less in its greatest dimension.

Surgery was generally recommended for patients with PTMC by guidelines [4, 5], but it could be associated with some permanent complications and cosmetic problems. Active surveillance was a new option recommended for patients with low-risk PTMC [4, 5]. However, a patient's willingness to adopt this strategy was an important element for implementation of this protocol [6, 7]. Moreover, no clinical or imaging method could reliably identify the small percent of invasive PTMC and prevent a large majority of PTMC patients from active surveillance [4, $7,8]$. Thus, finding less invasive alternatives is extremely helpful and important.

Radiofrequency ablation (RFA) is a minimally invasive treatment, which has been recommended as 
an effective strategy for thyroid benign nodules and recurrent thyroid cancer [9]. For the last few years, studies from multiple centers suggested that RFA was also an effective and safety alternative strategy for low-risk PTMC patients who were anxious about living with cancer or post-operative complications [10-13]. However, its application still remained controversial. At present, the post-ablation evaluations were mainly based on ultrasound (US), which could not indicate whether all the cancer cells were completely eliminated. Although histological examination after surgery was the gold standard of diagnosis, it could not be performed to the patients who refused surgery in the first place. Biopsy like fine-needle aspiration (FNA) and core-needle biopsy (CNB), were widely used for the diagnosis of thyroid nodules $[4,14]$, but they were not routinely used after thermal ablation. Only a few studies with small sample size had used FNA to evaluate the ablation areas of PTMC [15, 16]. However, the insufficient cellularity caused by tumor apoptosis and coagulative necrosis from thermal ablation could reduce the diagnostic accuracy of FNA for the ablation area [17, 18]. Comparing with FNA, $\mathrm{CNB}$ had higher diagnostic accuracy and a lower non-diagnostic rate to prevent further biopsy and unnecessary diagnostic surgery [14, 18-20]. To our knowledge, there were no large-scale studies about the clinical application of CNB after RFA for low-risk PTMC.

Therefore, the purpose of this study was to evaluate the clinical application of CNB for low-risk PTMC patients after RFA.

\section{Materials and Methods}

This retrospective study was approved by the Institutional Review Board of Chinese PLA General Hospital. Written information consent was obtained from all the patients prior to CNB and RFA.

\section{Patients}

All of the enrolled patients fulfilled the following criteria: (1) patients with PTC were confirmed by $\mathrm{CNB}$; (2) tumor with a maximum diameter no larger than $10 \mathrm{~mm}$; (3) absence of capsular infiltration and extrathyroidal extension; (4) no lymph nodes metastasis on US; (5) no distant metastasis; (6) patients who were unsuitable for surgery or rejected surgical treatment clearly; (7) no history of neck irradiation; (8) CNB was performed after RFA. The exclusion criteria were: (1) patients with aggressive histological PTC (e.g. tall cell, insular, columnar cell carcinoma) or benign nodule confirmed by CNB; (2) the maximum diameter of the tumor was more than $10 \mathrm{~mm}$; (3) capsular infiltration and extrathyroidal extension; (4) coagulation disorder or serious heart failure/ respiratory failure/ liver failure/ renal failure; (5) conscious disturbance or neck extension disorder that could not tolerate RFA procedure; (6) cervical lymph node metastasis or distant metastasis was found; (7) contra-lateral vocal cord paralysis; (8) CNB was not performed after RFA.

From June 2016 to November 2018, 231 patients with low-risk PTMC had CNB before RFA in our institution. Among them, ablation areas of 29 patients disappeared at 3 or 6 months after RFA. The remaining 202 patients with 211 low-risk PTMCs were included in this study.

\section{Pre-ablation assessment}

Before RFA, each tumor underwent US to evaluate the size, location, margin, shape, echogenicity, calcification and vascularity. The volume of tumor was calculated with the equations: $\mathrm{V}=n \mathrm{nabc} / 6$ ( $\mathrm{V}$ is the volume, while a is the largest diameter, $b$ and $c$ are the other two perpendicular diameters).

US were performed using a Siemens Acuson Sequoia 512 Ultrasound System (Siemens, Mountain View, CA, USA) or a Philips iU22 Ultrasound System (Philips Healthcare, Bothell, WA) or a Mindray M9 Ultrasound System (Mindray, Shenzhen, China). CNB and RFA were all performed using a Siemens Acuson Sequoia 512 Ultrasound System.

Contrast-enhanced ultrasound (CEUS) was used to evaluate the blood supply region of the tumor before and immediately after RFA. Sulphur hexafluoride (SonoVueR, Bracco. International, Milan, Italy) was used as ultrasound contrast agent. CEUS was performed after bolus injection of SonoVue (2.4 $\mathrm{ml}$ ), followed by a $5 \mathrm{ml}$ of normal saline flush. Real-time microbubble perfusions within the tumor and surrounding tissues were observed for a minimum of 2 minutes.

\section{Ablation procedures}

All RFA procedures were performed by an experienced US physician (Y.K.L, with more than 20 years' experience in thyroid US and interventional US). A bipolar RFA generator (CelonLabPOWER, Olympus Surgical Technologies Europe, Hamburg, Germany) and an 18-gauge bipolar RF applicator with $0.9 \mathrm{~cm}$ active tip were used (CelonProSurge micro 100-T09, Olympus Surgical Technologies Europe, Hamburg, Germany) in this study. Patients lay on an operating table in the supine position with the neck extended. Local anesthesia with $1 \%$ lidocaine was administered. If the distance between the tumor and critical cervical structures (trachea, cervical artery, jugular vein, esophagus and recurrent laryngeal nerve) was $<5 \mathrm{~mm}$, hydrodissection 
technique was used. Normal saline was injected using another needle (23 gauge) to separate the target tumor from critical structures in order to prevent thermal injury. RFA was performed using the trans-isthmic approach and moving-shot technique. The RFA power was $3 \mathrm{~W}$. If a transient hyperechoic zone did not form at the electrode tip within 5-10 seconds, the radiofrequency power was increased to 5-9 W. We enlarged the ablation area which exceeded the tumor edge (at least $3-5 \mathrm{~mm}$ ) to prevent marginal residue and recurrence [21, 22]. CEUS was performed immediately after the RFA procedure to evaluate the ablation area. If any enhancement existed, a complementary ablation could be performed.

During the procedure, special attention was given to the protection of critical cervical structures in order to prevent significant complications such as hematoma or nerve injury. Each patient was observed for 1-2 hours in the hospital while any complication occurring during and immediately after ablation were carefully evaluated according to the clinical signs and symptoms.

\section{Post-ablation assessment}

Clinical follow-ups were performed at 1, 3, 6, 12 months and every 6 months thereafter. The ablation area was evaluated by US. The development of metastatic lymph nodes was evaluated, and suspicious lesions were submitted to biopsy. The volume reduction was calculated as follows: VRR $=$ ([initial volume - final volume] $\times 100$ )/initial volume

\section{CNB procedure}

At 3 or 6 months after RFA, CNB was performed. CNB procedure was performed by a disposable 1.5- or 2.2-cm excursion, 20-gauge double-action, spring-loaded needle (BARD Magumn, Bard Peripheral Vascular Inc, Tempe, USA). Because the heated ablation area could be divided into the central zone, the peripheral zone and surrounding thyroid parenchyma by thermal ablation [23-25], CNB was performed at least in the central zone and peripheral zone of the ablation area, respectively. Because the diagnostic criteria of $\mathrm{CNB}$ have not been standardized, the $\mathrm{CNB}$ results were categorized into the same six categories as those for FNA cytology, according to the Bethesda System for Reporting Thyroid Cytopathology. Bethesda VI was defined as positive $\mathrm{CNB}$, Bethesda I, III and V as inconclusive results, and Bethesda II as negative CNB.

\section{Statistical analysis}

Statistical analysis was performed using the SPSS statistical software (Version 25.0). Continuous data were expressed as mean \pm SD (range). Wilcoxon signed rank tests were used to compare changes in the mean volume before RFA and at each follow-up point after RFA. A difference with $P<0.05$ was considered as statistically significant.

\section{Results}

Clinical characteristics of patients are presented in Table 1. Among the 202 patients (including 152 females and 50 males), 194 patients had one tumor, 7 patients had two tumors and 1 patient had 3 tumors. The mean initial diameter was $5.35 \pm 1.63 \mathrm{~mm}$ (range, $2.00-9.33 \mathrm{~mm}$ ) and the mean initial volume was $102.34 \pm 93.84 \mathrm{~mm}^{3}$ (range, $4.19-424.10 \mathrm{~mm}^{3}$ ). The mean age of patients was $42.79 \pm 10.13$ years (range, 20-74 years) and the mean follow-up time of $24.42 \pm 9.15$ months (range 3-42 months). There were 114 tumors located in the right lobe, 92 in the left lobe and 5 in the isthmus.

The mean power was $4.55 \pm 1.16 \mathrm{~W}$ (range 3-9 W). The mean RFA time was $153.81 \pm 88.11 \mathrm{~s}$ (range 34-530 s) and the mean energy was $767.68 \pm 461.78 \mathrm{~J}$ (range 160.00-2790.00 J).

The changes of mean volume and VRR at each follow-up point are shown in Table 2. Due to the enlarge ablation, the mean volume of the ablation areas at 1 and 3 months were significantly larger than the initial volume $(P<0.001)$. However, 3 months after RFA, the mean volume was gradually decreased (Figure 1 and Figure 2). The mean volume at each follow-up point was as follows: $387.84 \pm 270.43 \mathrm{~mm}^{3}$ (range $8.38-1524.67 \mathrm{~mm}^{3}$ ) at 1 months, $141.68 \pm 141.39$ $\mathrm{mm}^{3}$ (range 1.05-1123.09 $\mathrm{mm}^{3}$ ) at 3 months, $57.27 \pm 91.16 \mathrm{~mm}^{3}$ (range $0-791.66 \mathrm{~mm}^{3}$ ) at 6 months, $13.36 \pm 29.28 \mathrm{~mm}^{3}$ (range $0-209.43 \mathrm{~mm}^{3}$ ) at 12 months, $3.51 \pm 13.99 \mathrm{~mm}^{3}$ (range $0-128.28 \mathrm{~mm}^{3}$ ) at 18 months and $1.37 \pm 7.74 \mathrm{~mm}^{3}$ (range $0-73.30 \mathrm{~mm}^{3}$ ) at 24 months. At last follow-up point, the mean VRR was $99.14 \pm 4.18 \%$ (range $71.88-100 \%$ ). A total of 139 ablation areas $(65.88 \%)$ completely disappeared. The numbers of completely disappearance were $39(18.5 \%), 71(33.64 \%), 16(7.58 \%)$ and $13(6.16 \%)$ at 6 , 12,18 months and 24 months after RFA, respectively (Figure 3).

Table 1. Clinical characteristics of patients before RFA.

\begin{tabular}{ll}
\hline Characteristics & Data \\
\hline Age & $42.79 \pm 10.13$ (range 20-74) \\
Sex (female/male) & $152 / 50(75.25 \% / 24.75 \%)$ \\
Follow-up time (months) & $24.42 \pm 9.15$ (range 3-42) \\
Mean diameter (mm) & $5.35 \pm 1.63$ (range $2.00-9.33)$ \\
Volume $\left(\mathrm{mm}^{3}\right)$ & $102.34 \pm 93.84$ (range $4.19-424.10)$ \\
No. of patients & 202 \\
No. of tumors & 211 \\
One tumor & $194(91.94 \%)$ \\
Two tumors & $14(6.64 \%)$ \\
Three tumors & $3(1.42 \%)$ \\
Location & \\
right lobe & $114(54.03 \%)$ \\
left lobe & $92(43.60 \%)$ \\
isthmus & $5(2.37 \%)$ \\
\hline
\end{tabular}




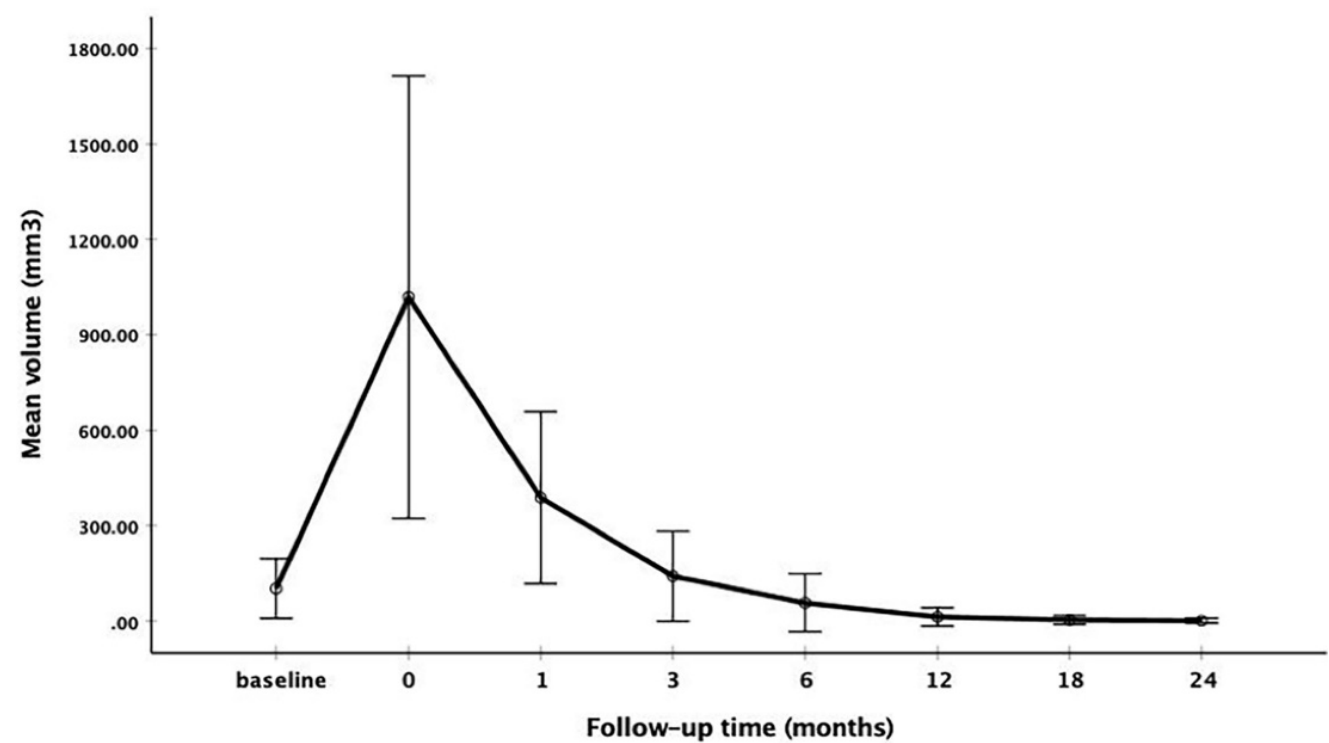

Figure 1. The changes of mean volume at each follow-up point

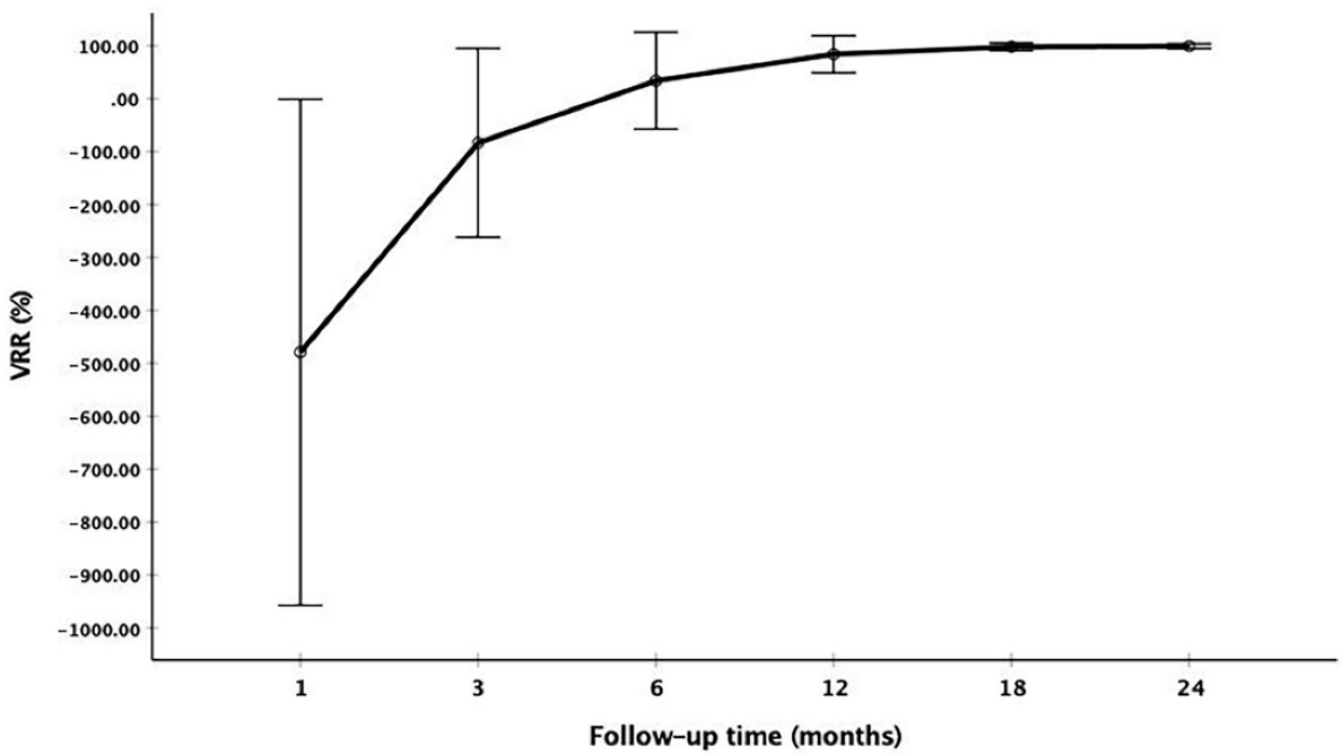

Figure 2. The changes of VRR at each follow-up point

Table 2. Changes of the volume and VRR after RFA at each follow-up.

\begin{tabular}{lllll}
\hline \multirow{2}{*}{ Time } & \multicolumn{2}{l}{ Volume of ablation area $\left(\mathrm{mm}^{3}\right)$} & VRR $(\%)$ & \multicolumn{1}{c}{ value } \\
& Mean volume & range & Mean VRR & range \\
\hline initial & $102.34 \pm 93.84$ & $4.19-424.10$ & NA & - \\
After RFA & $1018.17 \pm 696.03$ & $146.60-6217.55$ & NA & $<0.001$ \\
1 month & $387.84 \pm 270.43$ & $8.38-1524.67$ & $-479.28 \pm 478.53$ & $-2477.14-55.56$ \\
3 months & $141.68 \pm 141.39$ & $1.05-1123.09$ & $-83.51 \pm 178.54$ & $-1013.75-94.44$ \\
6 months & $57.27 \pm 91.16$ & $0-791.66$ & $34.00 \pm 91.67$ & $-462.50-100$ \\
12 months & $13.36 \pm 29.28$ & $0-209.43$ & $84.01 \pm 34.91$ & $-157.81-100$ \\
18 months & $3.51 \pm 13.99$ & $0-128.28$ & $97.81 \pm 6.99$ & $<0.001$ \\
24 months & $1.37 \pm 7.74$ & $0-73.30$ & $99.14 \pm 4.18$ & $<0.001$ \\
\hline
\end{tabular}

NA: not applicable

During the follow-up, CNB was performed at 3 or 6 months after RFA. Among CNB for 211 ablation areas, $75.83 \%(160 / 211)$ were performed in 3 zones and $24.17 \%(51 / 211)$ in two zones. The mean volume of ablation areas was $118.37 \pm 131.84 \mathrm{~mm}^{3}(1.05-1123.09$ $\mathrm{mm}^{3}$ ) when CNB was performed after RFA. A total of 3 ablation areas had positive $\mathrm{CNB}$ which were all
Bethesda VI in the peripheral zone and then underwent additional RFA. The changes of volume and VRR are showed in Table 3.

All the patients were well tolerable to RFA and CNB procedure. No recurrent or suspicious metastatic lymph nodes were detected. 

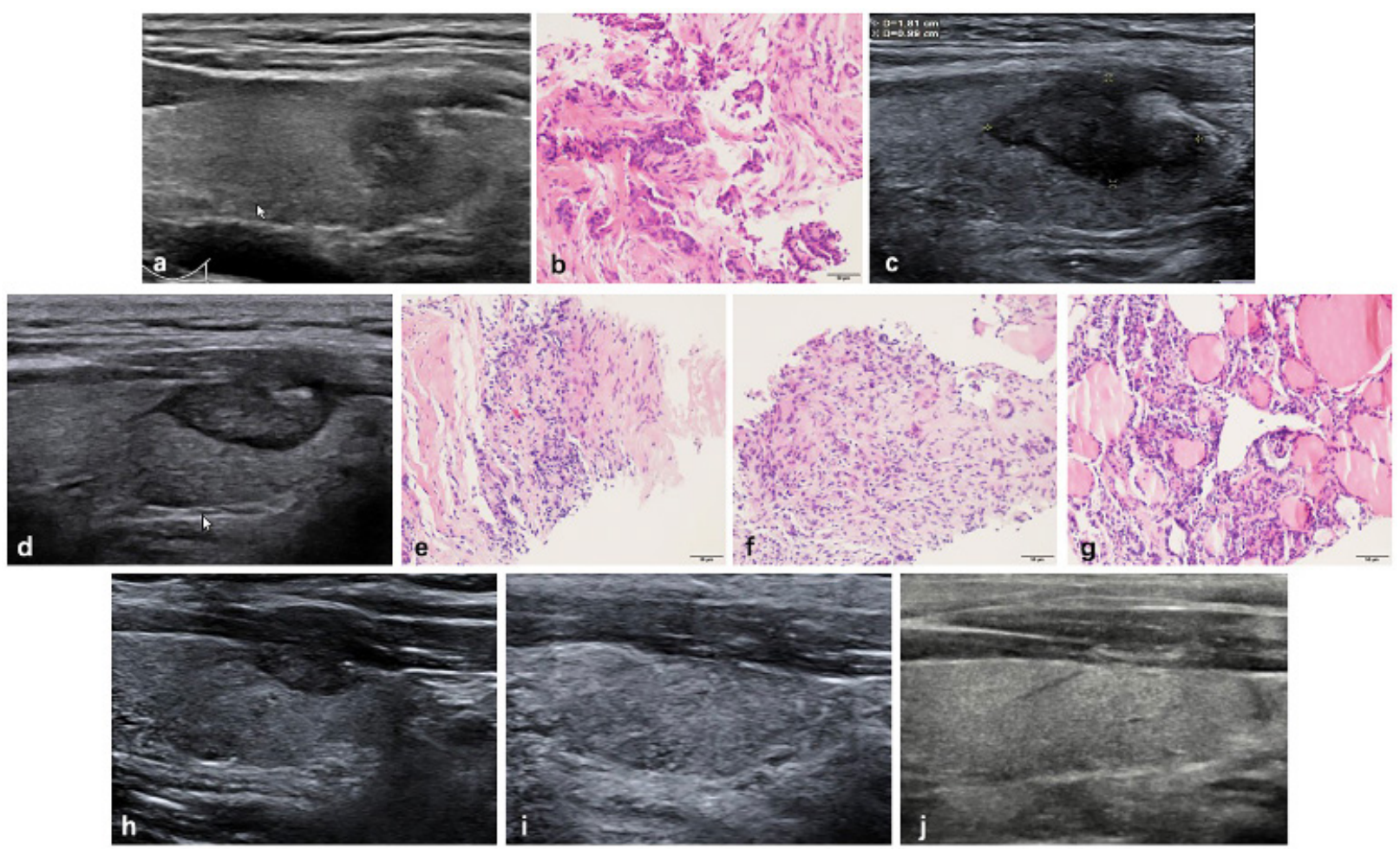

Figure 3. Radiofrequency ablation (RFA) treatment and follow-up of a 38-year-old male with a low-risk PTMC located in the left thyroid. (a, b) Before RFA, PTMC was diagnosed by CNB with an initial volume of $175.92 \mathrm{~mm}^{3}$ (arrow). Ablation area(arrow) was $1810.55 \mathrm{~mm}^{3}$ immediately after RFA. (c) At 1 months after RFA, the ablation area(arrow) was $1130.94 \mathrm{~mm}^{3}$. (d) At 3 months after RFA, the ablation area(arrow) was $351.85 \mathrm{~mm}^{3}$ (d). Post-ablation pathology showed degenerated and necrotic follicular epithelia with lymphocyte infiltration in the central zone(e), interstitial fibrous tissue hyperplasia with lymphocyte infiltration and multinucleated giant cell reaction in the peripheral zone( $\mathrm{f})$ and follicular epithelia hyperplasia with lymphocyte infiltration in the surrounding thyroid parenchyma(g). (h) At 6 months after RFA, the ablation area(arrow) was 131.94 mm³. (i) At 12 months after RFA, the ablation area was completely disappeared, and remained to be stable at 18 months after RFA (j).

Table 3. Volume changes of the ablation areas with positive CNB.

\begin{tabular}{|c|c|c|c|c|c|c|c|c|}
\hline \multirow[t]{2}{*}{ No. of tumor } & \multicolumn{5}{|c|}{ Volume $\left(\mathrm{mm}^{3}\right)$} & \multicolumn{3}{|l|}{ VRR (\%) } \\
\hline & Initial & After RFA & 1 month & 3 months & 6 months & 1 month & 3 months & 6 months \\
\hline 1 & 175.92 & 2089.10 & 560.76 & 167.55 & 109.95 & -218.75 & 4.76 & 37.5 \\
\hline 2 & 424.10 & 2457.18 & 678.56 & 329.86 & 301.58 & -60.00 & 22.22 & 28.89 \\
\hline 3 & 234.57 & 980.15 & 322.53 & 205.24 & 131.94 & -37.50 & 12.50 & 43.75 \\
\hline
\end{tabular}

\section{Discussion}

This study demonstrated the clinical application of CNB for low-risk PTMC after RFA. During a mean follow-up time of $24.42 \pm 9.14$ months, the mean VRR of low-risk PTMC was $99.14 \pm 4.18 \%$. No recurrent or suspicious metastatic lymph nodes were detected. A total of 3 ablation areas were diagnosed to have residual cancer by CNB and had additional RFA. All the patients were tolerant to the $\mathrm{CNB}$ procedure and no complications occurred. These results indicated that CNB could be used to evaluate the efficacy of RFA for low-risk PTMC.

For the last few years, several studies from multiple centers suggested that RFA was an effective and safe alternative strategy for low-risk PTMC [10-13]. After ablation, the volume reduction of ablation area was significant, and some tumors even disappeared in the follow-up. However, recently, Ma et al. [26] reported surgical confirmation of residual cancer in 11 PTC patients and 1 PTMC patient after previous ablation and suggested thermal ablation may result in incomplete treatment. Therefore, it is necessary to confirm the complete ablation of the target tumor to achieve the curative purpose. The Chinese expert consensus on thermal ablation for thyroid benign nodules, microcarcinoma and metastatic cervical lymph recommended that the efficacy of thermal ablation could be evaluated by biopsy at early stage of follow-up [27]. Two studies had used FNA to evaluate the ablation areas of PTMC at 1,6 and 12 months after thermal ablation $[15,16]$. Zhou et al [15] reported FNA was performed to the ablation area at 1,6 and 12 months after laser ablation (LA) for 30 low-risk PTMCs. In another study about LA for 64 low-risk PTMCs, FNA was performed in 3 zones of ablation areas at 1,6 and 12 months [16]. In our previous study, CNB was performed to the ablation areas at 3 months after RFA, however, the follow-up time was only 7.8 months [10]. In addition, CNB was also used to evaluate the ablation areas of recurrent thyroid cancer and benign nodules [28-30]. 
There were three reasons why we chose CNB instead of FNA to evaluate the ablation areas. First, although FNA was recommended for the diagnosis of thyroid nodules, it had limitations of low diagnostic accuracy and a high false-negative rate [20, 31-34]. The insufficient cellularity caused by tumor apoptosis and coagulative necrosis from thermal ablation could also reduce the diagnostic accuracy of FNA [17, 18]. Second, Comparing with FNA, CNB had higher diagnostic accuracy and a lower non-diagnostic rate to prevent further biopsy and unnecessary diagnostic surgery [14, 18-20]. Third, CNB was safe, well-tolerated and associated with a low incidence of complications when performed by experienced operators [14]. We already had the experience of CNB for the ablation area of low-risk PTMC [10], which could also reduce incidence of complications.

In this study, 3 ablation areas had positive CNB in the peripheral zone. The explanation might be that during the RFA procedure, the peripheral zone had a temperature between $41^{\circ} \mathrm{C}$ and $45^{\circ} \mathrm{C}$, which only cause sublethal and indirect damage leading to apoptosis or recovering from reversible injury [17]. Positive CNB suggested some cancer cells still existed, which might recover from the sublethal damage or not be completely eliminated by RFA. It was important to note that all the positive CNB was found in the peripheral zone, which suggested this zone was critical for complete ablation of low-risk PTMC. Similarly, several studies found that recurrent benign nodule after RFA showed regrowth in the peripheral zone [35-37]. However, unlike benign nodule, the primary purpose of RFA for low-risk PTMC was not to reduce symptom of pressure or solve cosmetic problem, but to obtain complete ablation. Therefore, the peripheral zone of low-risk PTMC should be ablated carefully and completely.

At present, the post-ablation evaluations for low-risk PTMC and benign nodule were both based on US. In this study, a total of 3 ablation areas had positive CNB, but the volumes were decreased. This rather contradictory result indicated that volume reduction was not equal to the disappearance of cancer cells. Only using US to evaluate the ablation area of low-risk PTMC was not enough, because it could neither provide diagnostic information about complete treatment nor detect residual cancer cells in the early period of follow-up.

This study including 202 patients with 211 low-risk PTMCs, has been not only the largest cohort of low-risk PTMC treated by thermal ablation thus far, but also the first study to demonstrate the value of CNB after ablation. It showed several advantages of CNB performed after ablation. First, CNB could provide a histological information on whether all the cancer cells were completely eliminated after ablation for low-risk PTMC. Second, compared with other evaluations by US, CNB could detect residual cancer cells earlier. Therefore, additional RFA could be performed in time to achieve complete ablation. Third, unlike previous studies which applied FNA three times after ablation, CNB in this study was only performed once after RFA. It could not only prevent multiple biopsies in multiple follow-up visits, but also avoid complications after biopsy.

There are some limitations in this study. First, it was a single-center retrospective study and the follow-up time was relatively short. Second, since we could not perform surgery on the ablation areas, the diagnostic performance of CNB could not be evaluated. However, in this study, $75.83 \%$ of CNB were performed in 3 zones of the ablation area and $24.17 \%$ in 2 zones, which could improve the diagnostic accuracy. Third, the sensitivity of US to detect central metastatic lymph nodes and multifocality was low, and their presences could not be completely excluded.

In conclusion, $\mathrm{CNB}$ is a feasible and effective evaluation for low-risk PTMC after RFA, which can detect residual cancer cells early. By CNB, RFA can be used as an efficacy and safety alternative for patients with low-risk PTMC.

\section{Abbreviations}

Core-needle biopsy: CNB; RFA: radiofrequency ablation; PTMC: papillary thyroid microcarcinoma; PTC: papillary thyroid carcinoma; US: ultrasound; VRR: volume reduction ratio; FNA: fine-needle aspiration; CEUS: contrast-enhanced ultrasound.

\section{Acknowledgements}

This study is supported by the National Natural Science Foundation of China (No. 81771834)

\section{Competing Interests}

The authors have declared that no competing interest exists.

\section{References}

1. Chmielik E, Rusinek D, Oczko-Wojciechowska M, Jarzab M, Krajewska J, Czarniecka A, et al. Heterogeneity of Thyroid Cancer. Pathobiology. 2018; 85: 117-29.

2. Bray F, Ferlay J, Soerjomataram I, Siegel RL, Torre LA, Jemal A. Global cancer statistics 2018: GLOBOCAN estimates of incidence and mortality worldwide for 36 cancers in 185 countries. CA: a cancer journal for clinicians. 2018; 68: 394-424

3. Leboulleux S, Tuttle RM, Pacini F, Schlumberger M. Papillary thyroid microcarcinoma: time to shift from surgery to active surveillance? The lancet Diabetes \& endocrinology. 2016; 4: 933-42.

4. Haugen BR, Alexander EK, Bible KC, Doherty GM, Mandel SJ, Nikiforov YE, et al. 2015 American Thyroid Association Management Guidelines for Adult Patients with Thyroid Nodules and Differentiated Thyroid Cancer: The American Thyroid Association Guidelines Task Force on Thyroid Nodules and Differentiated Thyroid Cancer. Thyroid. 2015; 26: 1-133.

5. Pacini F, Schlumberger M, Dralle H, Elisei R, Smit JW, Wiersinga W. European consensus for the management of patients with differentiated thyroid 
carcinoma of the follicular epithelium. European journal of endocrinology. 2006; 154: 787-803.

6. Haser GC, Tuttle RM, Su HK, Alon EE, Bergman D, Bernet V, et al. Active surveillance for papillary thyroid microcarcinoma: new challenges and opportunities for the health care system. Endocrine practice : official journal of the American College of Endocrinology and the American Association of Clinical Endocrinologists. 2016; 22: 602-11.

7. Ito $Y$, Nikiforov YE, Schlumberger M, Vigneri R. Increasing incidence of thyroid cancer: controversies explored. Nature Reviews Endocrinology. 2013; 9: 178.

8. Ito Y, Uruno T, Nakano K, Takamura Y, Miya A, Kobayashi K, et al. An Observation Trial Without Surgical Treatment in Patients with Papillary Microcarcinoma of the Thyroid. Thyroid. 2003; 13: 381-7.

9. Kim JH, Baek JH, Lim HK, Ahn HS, Baek SM, Choi YJ, et al. 2017 Thyroid Radiofrequency Ablation Guideline: Korean Society of Thyroid Radiology. Korean journal of radiology. 2018; 19: 632-55.

10. Zhang M, Luo Y, Zhang Y, Tang J. Efficacy and Safety of Ultrasound-Guided Radiofrequency Ablation for Treating Low-Risk Papillary Thyroid Microcarcinoma: A Prospective Study. Thyroid. 2016; 26: 1581-7.

11. Kim J-h, Baek JH, Sung JY, Min HS, Kim KW, Hah JH, et al. Radiofrequency ablation of low-risk small papillary thyroidcarcinoma: preliminary results for patients ineligible for surgery. International Journal of Hyperthermia. 2017; 33: 212-9.

12. Jeong SY, Baek JH, Choi $Y J$, Chung SR, Sung TY, Kim WG, et al Radiofrequency ablation of primary thyroid carcinoma: efficacy according to the types of thyroid carcinoma. International Journal of Hyperthermia. 2018; 34: 611-6.

13. Ding M, Tang X, Cui D, Chi J, Shi Y, Wang T, et al. Clinical outcomes of ultrasound-guided radiofrequency ablation for the treatment of primary papillary thyroid microcarcinoma. Clin Radiol. 2019; 74: 712-7.

14. Na DG, Baek JH, Jung SL, Kim JH, Sung JY, Kim KS, et al. Core Needle Biopsy of the Thyroid: 2016 Consensus Statement and Recommendations from Korean Society of Thyroid Radiology. Korean journal of radiology. 2017; 18: 217-37.

15. Zhou W, Jiang S, Zhan W, Zhou J, Xu S, Zhang L. Ultrasound-guided percutaneous laser ablation of unifocal T1N0M0 papillary thyroid microcarcinoma: Preliminary results. European radiology. 2017; 27: 2934-40.

16. Zhang L, Zhou W, Zhan W, Peng Y, Jiang S, Xu S. Percutaneous Laser Ablation of Unifocal Papillary Thyroid Microcarcinoma: Utility of Conventional Ultrasound and Contrast-Enhanced Ultrasound in Assessing Local Therapeutic Response. World J Surg. 2018; 42: 2476-84.

17. Chu KF, Dupuy DE. Thermal ablation of tumours: biological mechanisms and advances in therapy. Nature Reviews Cancer. 2014; 14: 199.

18. Chung SR, Suh CH, Baek JH, Choi YJ, Lee JH. The role of core needle biopsy in the diagnosis of initially detected thyroid nodules: a systematic review and meta-analysis. European radiology. 2018; 28: 4909-18.

19. Chung SR, Baek JH, Choi YJ, Sung TY, Song DE, Kim TY, et al. The Role of Core Needle Biopsy for the Evaluation of Thyroid Nodules with Suspicious Ultrasound Features. Korean journal of radiology. 2019; 20: 158-65.

20. Suh $\mathrm{CH}$, Baek JH, Lee JH, Choi YJ, Kim JK, Sung TY, et al. The Role of Core-Needle Biopsy as a First-Line Diagnostic Tool for Initially Detected Thyroid Nodules. Thyroid. 2016; 26: 395-403.

21. Ahmed M, Solbiati L, Brace CL, Breen DJ, Callstrom MR, Charboneau JW, et al. Image-guided tumor ablation: standardization of terminology and reporting criteria--a 10-year update. Radiology. 2014; 273: 241-60.

22. Teng D, Sui G, Liu C, Wang Y, Xia Y, Wang H. Long-term efficacy of ultrasound-guided low power microwave ablation for the treatment of primary papillary thyroid microcarcinoma: a 3-year follow-up study. Journal of cancer research and clinical oncology. 2018; 144: 771-9.

23. Nikfarjam M, Muralidharan V, Christophi C. Mechanisms of Focal Heat Destruction of Liver Tumors. Journal of Surgical Research. 2005; 127: 208-23.

24. Ahmed M, Brace CL, Lee FT, Goldberg SN. Principles of and Advances in Percutaneous Ablation. Radiology. 2011; 258: 351-69.

25. Shin JH, Baek JH, Ha EJ, Lee JH. Radiofrequency ablation of thyroid nodules: basic principles and clinical application. International journal of endocrinology. 2012; 2012: 919650-

26. Ma B, Wei W, Xu W, Wang Y, Guan H, Fan J, et al. Surgical Confirmation of Incomplete Treatment for Primary Papillary Thyroid Carcinoma by Percutaneous Thermal Ablation: A Retrospective Case Review and Literature Review. Thyroid. 2018; 28: 1134-42.

27. Ge MH, Xu D, Yang AK, Cheng RC, Sun H, Wang HC, et al. Expert consensus on thermal ablation for thyroid benign nodes, mocrocarcinoma and metastatic cervical lymph nodes(2018 edition). China cancer 2018, 27: 768-773(In Chinese)

28. Ha SM, Shin JY, Baek JH, Song DE, Chung SR, Choi YJ, et al. Does Radiofrequency Ablation Induce Neoplastic Changes in Benign Thyroid Nodules: A Preliminary Study. Endocrinology and metabolism (Seoul, Korea). 2019; $34: 169-78$

29. Lee SJ, Jung SL, Kim BS, Ahn KJ, Choi HS, Lim DJ, et al. Radiofrequency ablation to treat loco-regional recurrence of well-differentiated thyroid carcinoma. Korean journal of radiology. 2014; 15: 817-26.

30. Guang Y, Luo Y, Zhang Y, Zhang M, Li N, Zhang Y, et al. Efficacy and safety of percutaneous ultrasound guided radiofrequency ablation for treating cervical metastatic lymph nodes from papillary thyroid carcinoma. Journal of cancer research and clinical oncology. 2017; 143: 1555-62.
31. Suh $\mathrm{CH}$, Baek JH, Lee JH, Choi YJ, Kim KW, Lee J, et al. The role of core-needle biopsy in the diagnosis of thyroid malignancy in 4580 patients with 4746 thyroid nodules: a systematic review and meta-analysis. Endocrine. 2016; 54: 315-28.

32. Choi SH, Baek JH, Lee JH, Choi YJ, Ha EJ, Song DE, et al. Initial clinical experience with BRAFV600E mutation analysis of core-needle biopsy specimens from thyroid nodules. Clinical Endocrinology. 2016; 84: 607-13.

33. Richmond BK, Judhan R, Chong B, Ubert A, AbuRahma Z, Mangano W, et al. False-negative results with the Bethesda System of reporting thyroid cytopathology: predictors of malignancy in thyroid nodules classified as benign by cytopathologic evaluation. The American surgeon. 2014; 80: 811-6.

34. Malheiros DC, Canberk S, Poller DN, Schmitt F. Thyroid FNAC: Causes of false-positive results. Cytopathology : official journal of the British Society for Clinical Cytology. 2018; 29: 407-17.

35. Lim HK, Lee JH, Ha EJ, Sung JY, Kim JK, Baek JH. Radiofrequency ablation of benign non-functioning thyroid nodules: 4-year follow-up results for 111 patients. European radiology. 2013; 23: 1044-9.

36. Sim JS, Baek JH, Lee J, Cho W, Jung SI. Radiofrequency ablation of benign thyroid nodules: depicting early sign of regrowth by calculating vital volume. International journal of hyperthermia : the official journal of European Society for Hyperthermic Oncology, North American Hyperthermia Group. 2017; 33: 905-10.

37. Sim JS, Baek JH, Cho W. Initial Ablation Ratio: Quantitative Value Predicting the Therapeutic Success of Thyroid Radiofrequency Ablation. Thyroid. 2018; 28: 1443-9. 